\title{
ALGILANAN HİZMET KALITTESINIIN MÜŞTERİ MEMNUNİYETİNE ETKİSİ: ALGILANAN DEĞERİN ARACI ROLÜ
}

Şimal ÇELIKKOL ${ }^{1}$

$\ddot{O Z Z}$

\section{Anahtar Kelimeler: \\ Algilanan Hizmet Kalitesi, \\ Müşteri Memnuniyeti, \\ Algilanan Değer}

JEL Kodlari:

M21, M31

\author{
Received Date (Başvuru Tarihi): 14/11/2020 \\ Accepted Date (Kabul Tarihi): $\quad$ 23/12/2020 \\ Published Date (Yayın Tarihi): $\quad$ 25/12/2020
}

Keywords:

Perceived Service Quality Customer Satisfaction Perceived Value

JEL Codes: M21

M31

sürdürülebilir bir rekabet avantajı elde etme çabasındadır. Literatür yasanan bu yoğun rekabette, müşteri memnuniyetini etkileyen faktörleri anlamayı gerekli kilar. Bu nedenle araştırmada müşteri memnuniyetinin öncülü olarak değerlendirilen algılan hizmet kalitesi ve algılanan değeri içeren bir model önerilmiştir. Önerilen model test edilmesi için İstanbul'daki özel üniversite öğrencileri üzerinde anket uygulanmıştır. Kolayda örneklem yöntemiyle seçilen 419 öğrenciden anket verisi toplanmıştır. Toplanan anket verileri SSPS24 ve Amos-18 istatiksel programlarn yardımıyla analiz edilmiştir. Yapılan analizler algılanan değer ve algılanan hizmet kalitesinin müşteri memnuniyetini olumlu yönde etkilediğini göstermektedir. Aynca algılanan hizmet kalitesinin müşteri memnuniyetine etkisinde algılan değerin aracı rolü olduğu tespit edilmiştir. Elde edilen bulgular müşteri memnuniyetinin öncüllerini daha derinden anlamamıza yardımo olurken, mobil internet hizmeti sunan firmalara yönelik farkındalı yaratacă̆̆ değerlendirilmektedir.

M21 M31

\footnotetext{
${ }^{1}$ Dr. Öğr. Üyesi, Beykent Üniversitesi, simalcelikkol@beykent.edu.tr, $\quad$ https://orcid.org/0000-0002-5655-4833
} 


\section{EXTENDED ABSTRACT}

\section{THE EFFECT OF PERCEIVED SERVICE QUALITY ON CUSTOMER}

\section{SATISFACTION: THE INTERMEDIARY ROLE OF PERCEIVED VALUE}

\section{LITERATURE}

Mobile internet providers want to provide customer satisfaction by providing better internet service to their users and thus gain a competitive advantage. There are many firms located in Turkey, which offers mobile internet services and communication in the industry. However, companies operating in the sector are trying to profit and even survive in an extremely competitive environment. Intense competition in the industry requires understanding the factors that affect customer satisfaction. Because customer satisfaction is vital to gaining new customers and having more market share by retaining existing customers.

A model, including perceived service quality, perceived value, and customer satisfaction, was formed in the study. The study's model can help us understand how mobile internet service customers' satisfaction is formed and contribute to filling the gap in the literature for mobile internet services. Also, it is considered that the findings in the research will create awareness among the managers of companies offering mobile internet services.

\section{DESIGN AND METHOD}

Research hypotheses were tested using data collected from private university students in Istanbul. Therefore, the sample of the study consists of private university students. The data of the study were collected between 1 - 11 May 2019. The reason for collecting data from private university students in the study is that they are more active than other populations in mobile service usage behaviour (Momotaz, 2019).

Several procedures were used to increase the number of participants and to reduce anxiety among participants. Firstly, information on reducing anxiety in the participants was presented on the first page of the questionnaires. The information on the first page of the questionnaire contains information about writing the name of the survey, sharing the data with third parties, and the research aims. Also, the number of expressions in the questionnaire was kept very low (17 statements). Thus it is targeted to reduce cognitive fatigue in the participants. The questionnaires were distributed to the students by going to cafeterias, restaurants, and resting places where university students are concentrated. The return was obtained in 453 of the 700 questionnaires distributed (rate of return $64.71 \%$ ). The obtained survey data were analyzed according to outliers, and 34 questionnaire data were excluded from the study. Thus, 419 valid survey data were obtained in the study.

\section{FINDINGS AND DISCUSSION}

Perceived service quality $(=0.408,95 \% \mathrm{CI}=[0.3264,0.4894], \mathrm{t}=9.8314, \mathrm{p}<0.05)$ and perceived value $(=0.111,95 \% \mathrm{CI}=[0.0374,0.1836], \mathrm{t}=2.9689, \mathrm{p}<0.05)$ affect customer satisfaction significantly and positively. Hypothesis 1 and Hypothesis 2 are supported in the light of the findings. Also, the significance of the indirect effect $(\beta=0.032, \mathrm{SE}=0.0121,95 \% \mathrm{BCA} C \mathrm{CI}=[0.0101,0.0574])$ regarding the determination of the mediator role of perceived value indicates that perceived value has a mediator role in the effect of perceived service quality on customer satisfaction. Hypothesis 3 was supported in line with the findings obtained.

Research enriches our understanding of the antecedents of customer satisfaction. Customer satisfaction is a strategic issue to achieve success in the competitive world and gain a sustainable competitive advantage. Providing customer satisfaction strengthens companies' reputation and enables them to gain a competitive advantage by increasing their profitability. The findings of the study show that perceived service quality is the determinant of customer satisfaction. It is recommended that companies offering mobile internet services determine the expectations and needs 
of their customers and provide services accordingly. Meeting customers' expectations and needs will increase the service quality perceived by customers and create customer satisfaction. Besides, research findings show that perceived value is a vital variable in ensuring customer satisfaction. In this context, it is recommended that mobile internet service providers include applications that will positively affect customers' perceived value in their marketing policies. The literature documents that price reductions and invoicing transparency affect customers' perceived value perceptions and contribute significantly to customer satisfaction (Uddin and Akhter, 2012). In this context, it is recommended that companies reduce prices for mobile internet usage and ensure transparency in invoices. Although the study has strengths, it has some limitations. Therefore, these limitations should be taken into account when evaluating research findings. 


\section{GİRIŞ}

Mobil internet sağlayıcıları, kullanıcılarına daha iyi internet hizmeti vererek müşteri memnuniyeti sağlamak ve böylelikle rekabet avantajı elde etmek istemektedirler (Momotaz, 2019). Türkiye' de mobil internet hizmet sunmakta olan ve iletişim sektöründe yer alan birçok firma bulunmaktadır. Bununla birlikte sektörde faaliyet gösteren firmalar son derece rekabetçi bir ortamda kar elde etmeye ve hatta hayatta kalmaya çalışmaktadırlar. Sektör içerisinde yaşanan yoğun rekabet, müşteri memnuniyetini etkileyen faktörleri anlamayı gerekli kılmaktadır. Çünkü müşteri memnuniyeti, yeni müşteriler kazanmak ve mevcut müşterileri elde tutarak daha fazla pazar payına sahip olmak için önemli bir bileşen olarak ifade edilmektedir. Konu ile ilişkili olarak Momotaz (2019); yeni müşteriler kazanma, pazar payını arttırma ve karlılık gibi olumlu sonuçların, temel kaynağının müşteri memnuniyeti olduğunu düşünmektedir. Mbango ve Toerien (2019), Jeaheng, Al-Ansi ve Han (2020) ve García-Fernández, Gálvez-Ruíz, Fernández-Gavira, Vélez-Colón, Pitts ve Bernal-García (2018) gibi araştırmacılar ise; müşteri memnuniyetinin satın alma davranışı ve marka bağlılığı gibi tüketicilerin olumlu tutum ve davranışlarının oluşmasında doğrudan etkili olduğunu belirtmektedirler. Yapılan bu araştırmalar müşteri memnuniyetinin firmalara sürdürülebilir rekabet avantajı sağladığını göstermektedir.

Lewin (1938), müşteri memnuniyetini açıklamak için beklenti onay teorisini önermektedir. Teori, müşterilerin bir ürün ya da hizmeti tüketirken oluşan algılarının, beklentilerini aşması durumunda, o ürün ya da hizmetten memnun kalacaklarını belirtmektedir. Mason ve Paggiaro'ya (2012) göre; müşteri memnuniyeti, tüketim deneyiminin duygusal ve bilişsel bir değerlendirmesi olarak tanımlanmaktadır. Beklenti onay teorisi ve yapılan tanım, müşteri memnuniyetinin, beklentiden kaynaklanan son psikolojik durum olduğunu göstermektedir.

Hizmet sektöründe, müşteri memnuniyetinin, sunulan hizmetlere ilişkin tüketicinin isteklerini, beklentilerini ve ihtiyaçlarını karşılama kabiliyetine bağlı olduğu bilinmektedir. Birçok araştırmacının vurguladığı gibi müşteri memnuniyeti; hizmet organizasyonunun en önemli amacı olmakla birlikte (García-Fernández vd., 
2020; Konuk, 2019; Mbango ve Toerien, 2019), hizmetin kalitesi de müşteri memnuniyetinin ön koşulu olarak kabul edilmektedir (Lee, 2019). Bununla beraber hizmet sektöründe sunulan hizmetlerin kalite değerlendirmesi öznel olduğundan, hizmet kalitesinin değerlendirilmesi de müşterilerin algılarına göre şekillenmektedir. Dolayısı ile algılanan hizmet kalitesi, alınan hizmetler konusunda müşterilerin psikolojik değerlendirmesi olarak tanımlanmaktadır.

Yapılan araştırmalar algılanan hizmet kalitesinin, müşteri memnuniyeti üzerinde olumlu bir etkisinin olduğunu göstermektedir (Chen ve Chen, 2010; Slack, Singh ve Sharma, 2020; Mbango ve Toerien, 2019). Bununla birlikte Oriade (2013), müşteri memnuniyetinin sadece algılanan hizmet kalitesi ile değerlendirilmesinin, eksik bir değerlendirme olacağını ileri sürmektedir. Literatürde; algılanan hizmet kalitesi ile müşteri memnuniyeti ilişkisinde, özellikle algılanan değer olmak üzere diğer değişkenlerin de dikkate alınması önerilmektedir (Zabkar, Brenčič ve Dmitrović, 2010). Araştırmalar, algılanan değerin, algılanan hizmet kalitesinden etkilendiğini göstermektedir (Han, Al-Ansi, Olya ve Kim, 2019). Algilanan hizmet kalitesinin tipik olarak daha yüksek algılanan değere yol açtığının keşfedilmesiyle birlikte (Lai, Griffin ve Babin, 2009) pazarlama araştırmacıları ve uygulayıcıları, tüketicinin davranışlarını ve memnuniyet düzeylerini belirleyen faktörleri daha iyi anlamaya başlamıştır (Sürücü, Yeşilada ve Maslakçı, 2020). Bu nedenle, genel müşteri memnuniyetini anlamak için hem algılanan hizmet kalitesi hem de algilanan değerin etkisini aynı anda incelemenin faydalı olacağı ifade edilmektedir (Lee, 2019).

Literatür taramasında; algılanan hizmet kalitesinin, etkilemekte olduğu faktörler incelendiğinde, belirgin ilişkinin müşteri memnuniyeti ile ilgili olduğu görülmektedir. Müşteri memnuniyetinin öncüllerini tespit etmeye yönelik yapılan araştırmalarda; Islam, Rahman ve Nahar (2015) algılanan değerin; alg1lanan kalite ve müşteri memnuniyeti üzerinde olumlu etkiye sahip olduğunu gösteren çalışmasına rastlanmaktadır. Ayrıca, Momotaz'ın (2019); Bangladeş' deki mobil internet kullanımına yönelik yaptığı araştırmada, algılan kalitenin, algılan değer ve müşteri memnuniyeti ile doğrudan ilişkisi olduğu ifade edilmektedir. 
Yukarıda bahsedilen araştırmalar; algılanan kalite, algılanan değer ve müşteri memnuniyetinin farklı açılardan incelenebileceğini göstermektedir. Yapılan çalışmaları inceleyen Oriade (2013), algılanan hizmet kalitesinin, algılanan değer aracılığıyla müşteri memnuniyetine etkisinin incelemesinin, müşteri memnuniyetini daha iyi açıklayacağını, aksi durumda ise; elde edilen değerlendirmenin açıkça eksik olacağını belirtmektedir. Ayrıca müşteri memnuniyetinin, algılanan hizmet kalitesinin ve algılanan değer arasındaki ilişki birçok hizmet sektöründe kanıtlanmış olsa da iki kavram arasındaki ilişkinin mobil internet hizmetinde yeterince çalışılmadığ1 görülmektedir (Momotaz, 2019). Bu nedenle, mobil internet hizmetinde; müşteri memnuniyeti ve karar alma sürecini etkileyebilecek, algilanan hizmet kalitesi ile algılanan değer arasındaki ilişkiyi ortaya koyan bir araştırma yapmanın literatüre katkı sağlayacağ1 düşünülmektedir.

Araştırmada algılanan hizmet kalitesi, algılanan değer ve müşteri memnuniyetini içeren bir model oluşturulmuştur. Oluşturulan model mobil internet hizmetlere yönelik literatürdeki boşluğu kapatmaya yönelik katkı sağlamanın yanı sıra, mobil internet hizmeti alan müşterilerin memnuniyetlerinin nasıl oluştuğunu anlamamıza yardımeı olabilir. Ayrıca araştırmada elde edilen bulguların mobil internet hizmeti sunan firmaların yöneticilerinde farkındalık yaratacağı değerlendirilmektedir.

\section{LITERATÜR}

\subsection{Algılanan Hizmet Kalitesinin Müşteri Memnuniyetine Etkisi}

Müşterilere iyi düzeyde hizmet sunmanın, rekabet dünyasında başarıya ulaşmak ve hayatta kalmak için önemli olduğu belirtilmektedir (Wang, Lo ve Hui, 2003). Araştırmalar algılanan hizmet kalitesinin; satış ve finansal performansının artması, müşterilerde fiyat duyarsızlığı, müşteriyi elde tutma ve müşteri sadakati ile güçlü bir korelasyona sahip olduğunu belgelemektedir (lmayar, 2011). Yapılan araştırmalar hizmet kalitesine yönelik strateji oluşturan firmaların itibarının güçlendiği ve karlılığını artırarak firmalara önemli bir rekabet avantajı sağladığını göstermektedir (García-Fernández vd., 2020 Önemli bir rekabet avantajı sağlaması 
nedeniyle hizmet kalitesi, hizmet sektörlerinde faaliyet gösteren firmalar için önemli bir stratejik konu olarak görülmektedir (Spathis, Petridou ve Glaveli, 2004).

Hizmet kalitesi, müşterilerin; beklentileri, ihtiyaçları ve isteklerinin ne derecede karşılandığı ile ilgili algısı olarak ifade edilmektedir. Hizmet kalitesine yönelik algı, firma tarafından sunulan hizmetle ilgili müşterinin yaptı̆̆ değerlendirmenin sonucunda oluşmaktadır. Bu nedenle "hizmet kalitesi" konusunda çalışma yapan araştırmacılar, kalite yargılarının müşterinin algılarına, ihtiyaçlarına ve hedeflerine göre belirlendiğini vurgulamak için hizmet kalitesi yerine algılanan hizmet kalitesi terimini kullanmaktadır. Algılan hizmet kalitesi; müşterilerin kendilerine hizmetin sunulmasından önceki beklentileri ile hizmeti aldıktan sonra oluşan algı arasındaki fark olarak tanımlanmaktadır (Lee, 2019).

Lee ve Cheng (2015), algllanan hizmet kalitesinin müşteri memnuniyetin oluşmasında önemli bir faktör olduğunu ve müşteri memnuniyetin yalnızca algılanan hizmet kalitesiyle elde edildiğini belirtmektedir. Müşteri memnuniyeti ve algılanan hizmet kalitesinin birbiriyle ilişkili iki kavram olduğu uzun zamandır kabul edilmiş bir önermedir. Bununla birlikte ilişkinin yönü konusunda görüş birliği bulunmamaktadır. Görüş birliğinin sağlanamaması nedeniyle hizmet sektörüne yönelik yapılan bazı araştırmalarda algılanan hizmet kalitesi ile müşteri memnuniyeti eş anlamda kullanılmaktadır (Oriade, 2013; Hussain vd., 2015). Hâlbuki müşterilerin, hizmet kalitesi ve memnuniyete yönelik değerlendirme mekanizmalarının birbirinden farklı olduğu bilinmektedir (Žabkar, Brenčič ve Dmitrović, 2010). Müşterilerin hizmet kalitesini değerlendirmesi büyük ölçüde bilişsel bir süreç iken, memnuniyet hizmet deneyiminin duygusal bir sonuç olduğunu gözden kaçırmamak gerekmektedir (Lee ve Cheng, 2015). Diğer bir ifade ile alg1lanan hizmet kalitesi, hizmetlerin genel bir değerlendirmesini ifade ederken, memnuniyet alınan hizmetlerle ilgili deneyiminin genel değerlendirmesi olarak görülmektedir (Dauda ve Lee, 2016; Geore ve Kumar, 2014). Dolayısı ile müşteri memnuniyeti, ürün veya hizmetin algılanan kalitesine yönelik bir ölçüsüdür (Elmayar, 2011). Mevcut literatürden hareketle müşteri memnuniyeti, bir müşterinin bir hizmete veya ürüne eriştikten sonraki duygusal tepkisi olarak tanımlanabilmektedir. 
Literatürde, hizmet kalitesi ile müşteri memnuniyeti arasında güçlü bir ilişki olduğu iddia edilmektedir (Jeaheng vd., 2020; Ismail, Abdullah ve Francis, 2009). Yapılan araştırmalar, mevcut literatüre uygun olarak algılanan hizmet kalitesinin müşteri memnuniyetini olumlu yönde etkilediğini belgelemektedir (Uddin ve Akhter, 2012; Jeaheng vd., 2020; García-Fernández vd., 2020). Literatür ve yapılan araştırmalar doğrultusunda test edilmek üzere aşağıdaki hipotez geliştirilmiştir.

H1: Algılanan hizmet kalitesi müşteri memnuniyetini olumlu yönde etkiler.

\subsection{Algılanan Değerin Aracı Rolü}

Müşteri memnuniyetinin öncüllerini araştırmaya yönelik yapılan bir çalışmada algılanan değer konusunu incelemenin önemli olduğu düşünülmektedir. Çünkü algılanan değerin, algılanan hizmet kalitesi ile karşılaştırılması sonucunda, müşterilerin tutum ve davranışlarıyla daha yakından ilişkili olduğu görülmektedir (Momotaz, 2019). İki kavram arasındaki yakın ilişki nedeniyle son zamanlarda pazarlama araştırmacıları ve yöneticileri, müşteri memnuniyetini ve sadakatini açıklamak için anahtar stratejik bileşen olarak değer algılarına odaklanmaktadır (Uddin ve Akhter, 2012). Algılanan değer, hizmeti almak için yapılan fedakârlık ve maliyetlere dayalı olarak elde edilen faydalarının genel bir müşteri değerlendirmesi olarak tanımlanmaktadır (Hellier, Geursen, Carr ve Rickard, 2003).

Literatür, ekonomik sistemlerde müşteri memnuniyetinin algılanan değere bağlı olduğunu belirtmektedir (Jhandir, 2012). Bunun temel nedeni değer ile memnuniyet kavramlarının aynı değerlendiricinin yargıları doğrultusunda oluşmasından kaynaklanmasıdır. Memnuniyetin, algılanan değerin öncülü veya bir sonucu olması mümkündür. Nitekim Lim ve Morris (2006) müşteri memnuniyetinin yüksek düzeyde algılanan değere yol açtığını, Lai vd (2009) ise; müşterinin değer algılarının, müşteri memnuniyeti etkilediğini tespit etmişlerdir. Algılanan değerin, memnuniyetin bir öncülü veya bir sonucu olması mümkün olsa da araştırmacılar tarafından, algılanan değer, müşteri memnuniyetini doğrudan etkileyen önemli bir öncül olarak çok fazla destek görmektedir (García-Fernández vd., 2018).

Yapılan araştırmalarda, algılanan değerin önemli olduğu ve memnuniyetle olumlu ilişkilere sahip olduğu ortaya koyulmaktadır (Raza vd., 2012). Turel ve 
Serenko (2006) mobil hizmetler bağlamında yaptığı araştırmada, memnuniyet derecesinin algılanan değerin kapsamına bağlı olduğunu ve algılanan değerin daha yüksek müşteri memnuniyetine yol açtığını vurgulamaktadırlar. Choi Greenwell ve Lee (2018) ise, algılanan değerin hem doğrudan hem de dolaylı olarak müşteri memnuniyetini etkilediğini açıklamaktadır. Bu araştırmalar algılanan değerin, müşteri memnuniyetinin oluşmasında önemli bir öncül olduğunu göstermektedir.

Alandaki artan araştırmalara rağmen, algılanan değerin müşteri memnuniyeti ile nasıl etkileşime girdiğinin hala belirsiz olduğu düşünülmektedir (Eggert ve Ulaga, 2002; Oriade, 2013). Slack vd (2020) ve Samudro vd (2020) alg1lanan değerin müşteri memnuniyetiyle doğrudan ilişkisi olduğunu belirtirken Ismail vd (2009) algılan değerin düzenleyici bir etkisinin olduğunu, Konuk (2019) ve Momotaz (2019) ise; algılanan değerin aracı bir rol üstlendiğini vurgulamaktadır. Geçmiş araştırma bulguları doğrultusunda test edilmek üzere aşağıdaki hipotezler geliştirilmiştir.

$\mathbf{H}_{2}$ : Algilanan değer müşteri memnuniyetini olumlu yönde etkiler.

H3: Algzlanan hizmet kalitesinin müşteri memnuniyetine etkisinde algılanan değerin aracı rolü vardır.

Araştırma hipotezleri doğrultusunda geliştirilen araştırma modeli Şekil 1'de sunulmuştur.

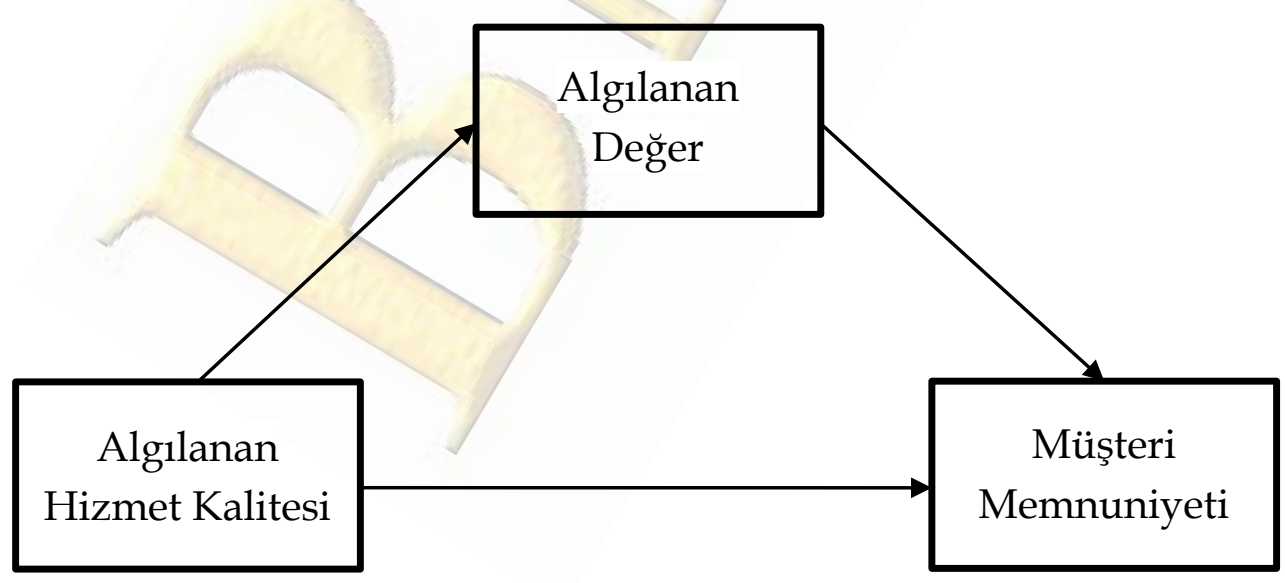

Şekil 1. Araştırma Modeli 


\section{METOT}

\subsection{Araştırma Yöntemi ve Örneklem}

Araştırma hipotezleri İstanbul'daki özel üniversite öğrencilerinden toplanan veriler kullanılarak test edilmiştir. Dolayısı ile çalışmanın örneklemi özel üniversite öğrencileri oluşturmaktadır. Araştırmanın verileri, 1 Mayıs - 11 Mayıs 2019 tarihleri arasında toplanmıştır. Araştırmada özel üniversite öğrencilerinin seçilme nedeni mobil hizmet kullanma davranışı açısından üniversite öğrencilerinin diğer popülasyonlara göre daha aktif olmasıdır (Momotaz, 2019). Ayrıca özel üniversitelerin daha merkezi yerlerde olması nedeniyle ulaşım kolaylığı sağlaması ise diğer bir tercih sebebidir. Araştırma için İstanbul'un tercih edilme sebebi ise İstanbul'un üniversite sayısı bakımında Türkiye'nin lideri olması ve Türkiye'deki üniversitelerin \%29,61'inin İstanbul 'da bulunmasıdır (İstanbul Valiliği, 2020).

Araştırmanın amaçları doğrultusunda hazırlanan anketler öncelikle 54 kişilik örneklem gruba uygulanmış ve anlaşılmayan ya da tereddüt yaşanan ifadelerin olup olmadığı tespit edilmiştir. Yapılan pilot çalışmada tereddüt yaşanan ifadelerin bulunmadığının anlaşılmasıyla beraber araştırmanın örneklem gruba uygulanmasına karar verilmiştir. Katılımcı sayısı artırmak ve katılımcılarda endişeyi azaltmak için birkaç prosedür uygulanmıştır. Öncelikle anketlerin birinci sayfasında katılımcılarda endişeyi azaltmaya yönelik bilgiler sunulmuştur. Anketin birinci sayfasında yer alan bilgilerde; ankete isim yazılması, verilerin 3. şahıslar ile paylaşılmayı ve araştırmanın amaçlarına dair bilgiler bulunmaktadır. Ayrıca anketteki ifade sayısı oldukça düşük tutularak (17 ifade) katılımcılarda bilişsel yorgunluğun azaltılması sağlanmıştır. Hazırlanan anketler üniversite öğrencilerin yoğun olarak bulunduğu kafeterya, lokanta ve dinlenme yerlerine gidilerek kolayda örneklem metoduyla seçilen öğrencilere dağıtılmıştır. Dağıtılan 700 anketten 453 tanesinde geri dönüş sağlanmıştır (geri dönüş oranı \%64,71). Elde edilen anket verileri aykırı değerlere göre incelenmiş 34 anket verisi araştırmadan çıkarılmıştır. Böylelikle araştırmada 419 geçerli anket verisi edilmiştir. Katılımcıların demografik özelliklerine yönelik veriler Tablo 1'de gösterilmiştir. 
Tablo 1. Katılımcıların Demografik Özellikleri

\begin{tabular}{|c|c|c|c|}
\hline Değişkenler & Kategoriler & S1klık & Yüzde \\
\hline \multirow{2}{*}{ Cinsiyet } & Erkek & 229 & 54,65 \\
\hline & Kadın & 190 & 45,35 \\
\hline \multirow{4}{*}{ Yaş } & 20 yaş altı & 308 & 73,51 \\
\hline & 21- 23 Yaş arası & 55 & 13,13 \\
\hline & $24-25$ yaş arası & 38 & 9,07 \\
\hline & 25 yaş ve üstü & 18 & 4,30 \\
\hline \multirow{2}{*}{ Medeni Durum } & Bekâr & 399 & 95,23 \\
\hline & Evli & 20 & 4,77 \\
\hline \multirow{5}{*}{$\begin{array}{l}\text { Internet hizmetini } \\
\text { kullanma süresi }\end{array}$} & 2 yildan az & 20 & 5,02 \\
\hline & $2-3$ yil & 41 & 9,79 \\
\hline & $3-4$ yil & 51 & 12,17 \\
\hline & $4-5$ y1l & 43 & 10,26 \\
\hline & 5 yıldan fazla & 263 & 62,77 \\
\hline \multirow{7}{*}{$\begin{array}{l}\text { Günlük mobil internet } \\
\text { hizmetini ortalama } \\
\text { kullanım süresi }\end{array}$} & $30 \mathrm{dk}^{\prime}$ dan az & 22 & 5,25 \\
\hline & $30 \mathrm{dk}-1$ saat & 60 & 14,32 \\
\hline & $1-2$ saat & 108 & 25,78 \\
\hline & 2-3 saat & 88 & 21,00 \\
\hline & 3-4 saat & 63 & 15,04 \\
\hline & 4-5 saat & 45 & 10,74 \\
\hline & $5-6$ saat & 33 & 7,88 \\
\hline
\end{tabular}

Tablo 1'de incelendiğinde katılımcıların çoğunluğunun bekâr $(\% 95,23)$ ve 20 yaş altında $(73,51)$ olduğu görülmektedir. Araştırmada örneklem grubunu üniversite öğrencilerinin oluşturması nedeniyle bu bulgular makul görülmektedir.

\section{2. Ölçekler}

Araştırmacının amaçları doğrultusunda oluşturulan ankette 17 ifade bulunmaktadır. Dört bölümde hazırlanan anketin ilk bölümünde katılımcıların demografik özelliklerini tespit etmeye yönelik olarak 5 ifade, ikinci bölümde algılanan hizmet kalitesini belirlemeye yönelik 6 ifade, üçüncü bölümde algılanan değeri ölçmeye yönelik 3 ifade, son bölümde ise; müşteri memnuniyetini ölçmeye yönelik olarak 3 ifade bulunmaktadır. 
Ölçekler 1 (tamamen katılmıyorum) 'den 5 (tamamen katılıyorum)'e kadar derecelendirilmiş 5'li likert tipindedir. Katılımcıların ölçeklere verdikleri puanlar artıkça ölçeğe yönelik algılarının da artacağı değerlendirilmektedir.

Demografik Özellikler; Katılımcıların, cinsiyet, yaş, medeni durum, internet hizmetini kullanma süresi ve günlük mobil internet hizmetini ortalama kullanım süresini belirmeye yönelik olarak 5 ifade bulunmaktadır.

Algılanan Hizmet Kalitesi Ölçeği: Literatürde sıklıkla kullanılan ve Parasuraman, Zeithaml ve Berry (1988) tarafından geliştirilmiş olan ölçeğin, Baran (2020) tarafından uyarlanmış versiyonu kullanılmıştır. 5’li Likert tipinde hazırlanan ölçekte 6 ifade yer almaktadır. Örnek ifadeler; "İnternet firmam müşterilerine bireysel ilgi gösteriyor." ve "Müşterilerine istekli bir şekilde hizmet veriyor." şeklindedir.

Algılanan Değer Ölçeği: Algılanan değer Zeithaml (1988) tarafından geliştirilen ve Özbek (2016) tarafından uyarlanmış versiyonu kullanılmıştır. 5'li Likert tipinde hazırlanan ölçekte 3 ifade yer almaktadır. Örnek ifadeler; mobil internete hizmeti için ödediğim fiyatın karşılığı aldığımı düşünüyorum" ve "mobil internet firmamım iyi olduğunu düşünüyorum" şeklindedir.

Müşteri Memnuniyeti Ölçeği: Müşterilerin memnuniyetini ölçmeye yönelik olarak, Han ve Ryu (2012) tarafından geliştirilen ve Bilgin (2017) tarafından Türkçeye uyarlanan ölçek kullanılmıştır. 5'li Likert tipinde hazırlanan ölçekte 3 ifade yer almaktadır. Örnek ifadeler; "İnternet firmamdan aldı̆̆ım hizmetten memnunum." ve "Önceki deneyimlere göre şu anki mobil hizmet firmam daha iyi hizmet veriyor." şeklindedir.

\section{BULGULAR}

\subsection{Geçerlik}

Araştırma modelinde kullanılan değişkenlerin yapı boyutlarını keşfetmek için faktör analizi yapılmıştır. Öncelikle araştırmada önerilen faktör yapılarının gerçek verilerle gerçekten tutarlı olup olmadığını kontrol etmek için Açımlayıcı Faktör Analizi (EFA) yapılmıştır. EFA, Varimax rotasyonuyla temel bileşenler ekstraksiyon 
yöntemi kullanılarak yapılmıştır (Tablo 2). Kaiser-Meyer-Olkin (KMO) değerleri 0,7'den büyük olması verilerin faktör analizi için yeterli büyüklükte olduğunu göstermektedir. Faktör analizinde, Bartlett'in küresellik testi anlamlı bulunmuştur $(p<0,001)$. Elde edilen bulgular ankette yer alan değişkenlere yönelik faktör analizinin yapılabileceğini göstermektedir (Tabachnick, Fidell ve Ullman 2007). Değişkenlere yönelik yapılan keşfedici faktör analiz sonuçları Tablo 2 de sunulmuştur. Model uyum indekslerinin tespitine yönelik yapılan doğrulayıcı faktör analiz sonuçları ise; araştırmada önerilen modelin iyi uyum değerlerine sahip olduğunu göstermektedir $(\mathrm{CMIN} / \mathrm{df}=3.195, \mathrm{GFI}=0.901, \mathrm{CFI}=0.897, \mathrm{IFI}=0.852$, RMSEA = 0,045).

Tablo 2. Faktör Analizi Sonuçları

\begin{tabular}{|c|c|c|c|c|}
\hline Değişken & İfade & Faktör yükü & Eigenvalue & $\begin{array}{c}\text { Toplam } \\
\text { Açıklanan } \\
\text { Varyans }\end{array}$ \\
\hline \multirow{7}{*}{$\begin{array}{c}\text { Algilanan } \\
\text { Hizmet } \\
\text { Kalitesi }\end{array}$} & AHK 1 & 0,621 & \multirow{6}{*}{2,983} & \multirow{6}{*}{49,724} \\
\hline & AHK 2 & 0,688 & & \\
\hline & AHK 3 & 0,759 & & \\
\hline & AHK 4 & 0,777 & & \\
\hline & AHK 5 & 0,721 & & \\
\hline & AHK 6 & 0,652 & & \\
\hline & \multicolumn{4}{|c|}{$\begin{array}{l}\mathrm{KMO}=0,810 ; \text { Bartlett's Test of Sphericity }=853,685 ; \mathrm{df}=15 \text {; } \\
\text { Sig. }=0,000\end{array}$} \\
\hline \multirow{4}{*}{$\begin{array}{l}\text { Algilanan } \\
\text { Değer }\end{array}$} & AD 1 & 0,787 & \multirow{3}{*}{1,986} & \multirow{3}{*}{66,215} \\
\hline & AD 2 & 0,866 & & \\
\hline & AD 3 & 0,786 & & \\
\hline & \multicolumn{4}{|c|}{$\begin{array}{l}\mathrm{KMO}=0,857 ; \text { Bartlett's Test of Sphericity }=374,631 ; \text { Sig. }=0,000 ; \mathrm{df}= \\
3\end{array}$} \\
\hline \multirow{4}{*}{$\begin{array}{l}\text { Müşteri } \\
\text { Memnuniyeti }\end{array}$} & MM 1 & 0,797 & \multirow{3}{*}{1,934} & \multirow{3}{*}{64,572} \\
\hline & MM 2 & 0,837 & & \\
\hline & MM 3 & 0,776 & & \\
\hline & \multicolumn{4}{|c|}{$\begin{array}{l}\mathrm{KMO}=0,771 ; \text { Bartlett's Test of Sphericity }=332,697 ; \text { Sig. }=0,000 ; \mathrm{df}= \\
3\end{array}$} \\
\hline
\end{tabular}

Araştırmada öz değeri 1'i aşan 3 faktör bulunmaktadır. Tüm faktör yükleri önerilen kesme noktası olan 0,40'ın üzerindedir (Nunnally ve Burnstein 1994). Yüksek faktör yükleri, ölçeklerin yakınsak geçerliliğe sahip olduğu sonucuna varmak için sebep verir. Ayrıca ıraksak geçerliliğin tespit edilmesi maksadıyla Çıkarılan Ortalama Varyans (AVE) değerleri ölçülmüştür (Tablo 3). AVE değerlerinin 0,5'den yüksek olması ve her bir AVE değerinin karekökünün değişkenler arasındaki 
korelasyondan fazla olması değişkenlerin ıraksak geçerliliğinin olduğunu göstermektedir (Fornell ve Larcker, 1981; Sürücü ve Maslakçı, 2020).

\subsection{Güvenirlik}

Araştırma kapsamına alınan ölçeklerin güvenirliğinin tespit edilmesine yönelik olarak Bileşik Güvenilirlik ve Cronbach Alpha katsayı hesaplanmıştır. Elde dilen değerler Tablo 3’de sunulmuştur.

Tablo 3. Güvenilirlik Sonuçları

\begin{tabular}{|l|c|c|c|c|}
\hline \multicolumn{1}{|c|}{ Değişkenler } & $\begin{array}{c}\text { İfade } \\
\text { Sayısı }\end{array}$ & AVE & $\begin{array}{c}\text { Birleşik } \\
\text { Güvenirlik }\end{array}$ & $\begin{array}{c}\text { Cronbach } \\
\text { Alfa }\end{array}$ \\
\hline Algılanan Hizmet Kalitesi & 6 & 0,497 & 0,855 & 0,794 \\
\hline Algılanan Değer & 3 & 0,662 & 0,854 & 0,743 \\
\hline Müşteri Memnuniyeti & 3 & 0,645 & 0,854 & 0,725 \\
\hline
\end{tabular}

Yukarıda sunulan tablo, araştırma kapsamına alınan değişkenlerinin birleşik güvenirlik ve Cronbach Alfa değerleri 0,7 ve üzerinde olduğunu göstermektedir. Sürücü ve Maslakçı (2020), bu değerlerin 1'e yaklaştıkça güvenirliğin arttığını ve araştırmanın sağlıklı sonuç vermesi için ölçeğin güvenirlik değerinin 0,7 ve üzeri olması gerektiğini belirtmektedir. Elde edilen bulgular araştırma kapsamına alınan değişkenlerin güvenilir olduğunu söylemek mümkündür.

\subsection{Korelasyon Analizi}

Korelasyon analizinden önce verilerin normal dağılım gösterip göstermediğini anlamak için çarpıklık ve basıklık katsayıları incelenmiştir (Sürücü ve Maslakçı, 2020). Algılanan hizmet kalitesinin çarpıklık katsayısı -0,474 ve basıklık katsayısı 0,115, algılanan değeri çarpıklık katsayısı -0,646 ve basıklık katsayısı 0,445, müşteri memnuniyeti çarpıklık katsayısı $-0,769$ ve basıklık katsayısı 0,823'tür. $-1,5$ ile +1,5 arasındaki çarpıklık ve basıklık değerleri verilerin normal bir dağılıma sahip olduğunu göstermektedir (Hair, Hult, Ringle ve Sarstedt, 2014). Verilerin normal dağılım göstermesi nedeniyle değişkenler arasındaki korelasyonu belirlemek için analizde Pearson Korelasyon değerleri dikkate alınmıştır.

Tablo 4'deki veriler, alg1lanan hizmet kalitesinin algılanan değer $(r=0,255, p$ $<0,05)$ ve müşteri memnuniyeti $(r=0,429$, p <0,05) ile pozitif yönlü anlamlı bir 
korelasyon olduğunu göstermektedir. Ayrıca algılanan değer, müşteri memnuniyeti ile de pozitif yönlü anlamlı bir korelasyonu vardır $(r=0,222, \mathrm{p}<0,05)$.

Tablo 4. Ortalama, Standart Sapma, Korelasyonlar

\begin{tabular}{|l|c|c|c|c|c|}
\hline \multicolumn{1}{|c|}{ Değişkenler } & Ortalama & $\begin{array}{c}\text { Standart } \\
\text { Sapma }\end{array}$ & $\mathbf{1 .}$ & $\mathbf{2}$. & $\mathbf{3 .}$ \\
\hline 1. Algılanan Hizmet Kalitesi & 3,751 & 0,747 & $\mathbf{( 0 , 7 0 4 )}$ & & \\
\hline 2. Alg1lanan Değer & 3,734 & 0,833 & $0,255^{* *}$ & $\mathbf{( 0 , 8 1 4 )}$ & \\
\hline 3. Müşteri Memnuniyeti & 3,921 & 0,764 & $0,429^{* *}$ & $0,222^{* *}$ & $\mathbf{( 0 , 8 0 3 )}$ \\
\hline
\end{tabular}

${ }^{* *}$ Korelasyon 0,05 düzeyinde (2 kuyruklu) anlamlıdır. Parantez içinde kalın olarak yazılmış rakamlar AVE nin karekök değerlerini ifade etmektedir.

\subsection{Hipotez Testleri}

Araştırma hipotezlerini test etmek için Hayes (2013) tarafından SPSS'e eklenti olarak geliştirilen Process Macro kullanılmıştır. Model özeti Tablo 5'de, yapılan analiz sonuçları ise Tablo 6'de sunulmuştur.

Tablo 5. Model Özeti

\begin{tabular}{|c|c|c|c|c|}
\hline $\mathbf{R}$ & R-Sq & MSE & F & P \\
\hline, 7901 &, 6243 & 0,4389 & 470,2182 &, 0000 \\
\hline
\end{tabular}

Tablo 5, araştırma modelinin özetini göstermektedir. Buna göre alg1lanan hizmet kalitesi ve algılanan değer, müşteri memnuniyetindeki varyansın \%62,43'ünü açıkladığını göstermektedir. Ayrıca p değerinin 0,05'den küçük olması modelin anlamlılı̆̆ını göstermektedir.

Tablo 6. Bootstrap Sonuçları

\begin{tabular}{|l|l|c|c|c|c|}
\hline Hipotezler & \multicolumn{1}{|c|}{ Yol } & Etki & SH & LLCI & ULCI \\
\hline H1 & AHK $\rightarrow$ MM & 0,408 & 0,0415 & 0,3264 & 0,4894 \\
\hline H 2 & AD $\rightarrow$ MM & 0,111 & 0,0372 & 0,0374 & 0,1836 \\
\hline H3 & Dolaylı Etki (AHK $\rightarrow$ AD $\rightarrow$ MM) & 0,032 & 0,0121 & 0,0101 & 0,0574 \\
\hline
\end{tabular}

Tablo 6'de görülebileceği gibi algılanan hizmet kalitesi $(\beta=0,408,95 \%$ CI= $[0,3264,0,4894], t=9,8314, p<0,05)$ ve alg1lanan değer $(\beta=0,111,95 \% C I=[0,0374$, 0,1836], $t=2,9689, p<0,05)$ müşteri memnuniyetini anlamlı ve pozitif yönde 
etkilemektedir. Elde edilen bulgular ışığında hipotez 1 ve hipotez 2 desteklenmiştir. Ayrıca algılanan değerin aracı rolünün tespitine yönelik olarak dolaylı etkinin anlamlı olması $(\beta=0,032, \mathrm{SE}=0,0121,95 \% \mathrm{BCA} C \mathrm{CI}=[0,0101,0,0574])$ algilanan hizmet kalitesinin müşteri memnuniyetine etkisinde algilanan değerin aracı rolünün olduğunu göstermektedir. Elde edilen bulgu doğrultusunda hipotez 3 desteklenmiştir.

\section{TARTIŞMA VE SONUÇ}

Müşteri memnuniyeti pazarlama maliyetlerinin azaltılması, mevcut müşterilerin elde tutulması ve daha fazla yeni müşterinin elde edilmesinde kaldıraç etkisi gördüğgünden firmalara önemli bir pazarlama avantajı sağlamaktadır. Ek olarak, müşteri memnuniyeti bir firmanın rekabet edebilirliği ve karlılığı için bir ön koşul olarak kabul edilmektedir. Bu nedenle firmalar, yüksek düzeyde müşteri memnuniyetini sağlamaya çalışmaktadır. Pazarlama araştırmacıları, müşteri memnuniyetinin öncüllerini anlamaya yönelik birçok araştırma yapmıştır. He ne kadar yapılan araştırmalarda algılanan hizmet kalitesi ve algılanan değerin, müşteri memnuniyetinin öncülü olduğu tespit edilse de bu değişkenlerin ilişkisinin yönü konusunda görüş birliği bulunmamaktadır. Ayrıca değişkenler arasındaki ilişki, mobil internet hizmetine yönelik literatürde yeterince araştırılmamıştır (Momotaz, 2019). Türkiye'deki mobil internet kullanımına yönelik yapılan bu araştırma literatürdeki boşluğu kapatmaya yönelik katkı sağlamanın yanı sıra müşteri memnuniyetine yönelik literatür genişletmektedir. Araştırmanın ana bulguları aşağıdaki gibidir.

Araştırmada algılanan hizmet kalitesinin müşteri memnuniyetini anlamlı ve pozitif yönde etkilediği tespit edilmiştir. Aslında bu bulgu beklenen bir sonuçtur. Çünkü algılanan hizmet kalitesi ve müşteri memnuniyeti aynı değerlendiricinin algıları sonucunda oluşmaktadır. Dolayısı ile bu iki kavram birbirinin destekler niteliktedir. Algılanan hizmet kalitesi, müşterilerin aldıkları hizmeti, beklentileriyle karşılaştırması sonucunda oluşmaktadır. Diğer bir ifade ile müşterilerin beklentileri ile gerçek performans arasındaki fark, algılanan hizmet kalitesi olarak yansıtılmaktadır. Hizmet kalitesi müşteri beklenti ve ihtiyaçlarını karşılıyorsa 
müşteri memnuniyeti sağlanacaktır. Aksi durumda ise müşteri memnuniyeti sağlanamayacaktır. Mevcut durum, hizmet kalitesi olmadan müşteri memnuniyetini inşa etmenin zor olacağı anlamına gelmektedir. Araştırmanın bulgusu geçmiş araştırma bulguları ile tutarlı olarak (Slack, Singh ve Sharma, 2020; Mbango ve Toerien, 2019), algılanan hizmet kalitesinin müşteri memnuniyeti üzerinde güçlü bir etkiye sahip olduğunu ve algılanan hizmet kalitesinin müşterilerde yüksek derecede memnuniyet oluşturduğunu göstermektedir.

Araştırmada elde edilen diğer bulgu ise algılan değerin müşteri memnuniyetini anlamlı ve pozitif yönde etkilediğidir. Hizmet alımlarında algılanan değer, verilenle (maliyetler) alınanların (faydaların) karşılaştırılmasında, müşterilerin algılarına göre alınan hizmetin faydasına ilişkin genel değerlendirmesi olarak görülebilir (Chen ve Tsai, 2008). Öz sermaye teorisine göre bir müşteri, parasal ödemeler ve müşterilerin yaşadığı zaman tüketimi, enerji tüketimi ve stres gibi parasal olmayan fedakârlıklar dâhil olmak üzere, aldığı hizmete yönelik olarak algılanan maliyeti hesaplar. Bu göreceli hesaplamaya göre eğer müşteri yaptığı fedakârlıkların karşılığını alıyorsa müşteri memnuniyeti oluşacaktır. Aksi durumda ise memnuniyetsizlik oluşur. Dolayısı ile müşteri memnuniyeti, algılanan değerden etkilenir. Sonuç olarak memnuniyet derecesi, algılanan değerin boyutuna bağlıdır ve algılanan değerin yüksek olması, daha yüksek düzeyde müşteri memnuniyetine yol açar. Bu bakış açısıyla araştırmanın bulgusu makul görülebilir.

Araştırmada elde edilen son bulgu ise, algılanan hizmet kalitesinin müşteri memnuniyetine etkisinde algılanan değerin aracı rolünün tespit edilmesidir. Aslında algılan hizmet kalitesi, algılan değer ve müşteri memnuniyeti arasındaki ilişkiye yönelik çalışmalar olmakla birlikte bu değişkenler arasında ilişkinin yönü hakkında görüş birliği bulunmamaktadır. Slack vd (2020) algılanan hizmet kalitesi ve algılanan değerin, müşteri memnuniyeti üzerinde doğrudan bir etkisinin olduğunu savunurken, Ismail vd (2009) algilanan değerin bu ilişkide düzenleyici etkisinin olduğunu, Konuk (2019) ve Momotaz (2019) ise alg1lanan değerin aracı bir rol üstlendiğini belirtmektedir. Araştırmamızın bulgusu algılanan değerin aracı rolünü ampirik olarak belgeleyerek literatürdeki bu belirsizliği açıklamaya yönelik katkı sağlamaktadır. 
Sonuç olarak; araştırma müşteri memnuniyetinin öncüllerine yönelik anlayışımızı zenginleştirmektedir. Müşteri memnuniyeti rekabet dünyasında başarıya ulaşmak ve sürdürülebilir rekabet avantajı elde etmek için stratejik konudur. Müşteri memnuniyeti sağlamak firmaların itibarını güçlendirir ve karlılıklarını artırarak rekabet avantajı elde etmelerini sağlar. Araştırmanın bulguları algılanan hizmet kalitesinin müşteri memnuniyetinin belirleyicisi olduğunu göstermektedir. Mobil internet hizmeti sunan firmaların müşterilerin beklenti ve ihtiyaçlarını tespit edip buna göre hizmet sunmaları önerilmektedir. Müşterilerin beklenti ve ihtiyaçlarının karşılanması, müşterilerde algılanan hizmet kalitesini artırarak müşteri memnuniyetin oluşmasını sağlayacaktır. Ayrıca araştırma bulguları algılan değerin de müşteri memnuniyetinin sağlanmasında önemli bir değişken olduğunu göstermektedir. Bu bağlamda mobil internet hizmeti sağlayıcıların müşterilerde algılanan değeri olumlu yönde etkileyecek uygulamaları pazarlama politikalarına dâhil etmesi önerilir. Literatür fiyat indirimlerin ve faturalama şeffaflı̆̆ının müşterilerde algılan değeri algılarını etkilediğini ve müşteri memnuniyetinin oluşmasına önemli katkılar sağladığını belgelemektedir (Uddin ve Akhter, 2012). Bu bağlamda firmaların mobil internet kullanımına yönelik fiyat indirimine gitmesi ve faturalarda şeffaflı̆̆ı sağlanması önerilir.

Araştırmanın güçlü yönleri olmakla birlikte bazı sınırlılıkları mevcuttur. Bu nedenle araştırma bulguları değerlendirilirken bu sınırlılıklar dikkate alınmalıdır. Öncelikle araştırma özel üniversite öğrencileri üzerinden yapılmıştır. Örneklem grubu araştırmanın genelleştirilebilmesi konusunda yetersizdir. Ayrıca araştırmanın kesitsel tasarımı, değişken arasındaki nedensel ilişkileri açıklamaya imkân vermemektedir. Araştırmada sosyo-demografik faktörlerin müşteri memnuniyetine etkisi araştırılmamıştır. Bu kısıtlamalar ortadan kaldırarak yapılacak araştırmalar müşteri memnuniyetinin öncüllerini anlamak açısından faydalı olacaktır. Son olarak literatür, hizmet bağlamında kalite algısı, müşteri veya hizmet sağlayıcı perspektiflerinden incelenebileceğini belirtmektedir (Oriade, 2013). Bu bağlamda ileride yapılacak araştırmalarda bu iki perspektifi araştıran araştırmacılar, algılan kalite ile müşteri memnuniyet ilişkisine yönelik farklı bakış açıları sunabilirler. 


\section{KAYNAKÇA}

Baran, G. (2020). Deneyimsel pazarlama ve algilanan hizmet kalitesinin marka sadakatine etkisi: Kahve mağazaları örneği. Yayımlanmamış Yüksek Lisans Tezi, Aydın Adnan Menderes Üniversitesi, Sosyal Bilimler Enstitüsü, Aydın.

Bilgin, Y. (2017). Restoran işletmelerinde hizmet kalitesi, müşteri memnuniyeti ve müşteri sadakatinin ağızdan ağıza pazarlamaya etkisi. İşletme Araştırmaları Dergisi, 9(4), 33-62.

Chang, K. C., Chen, M. C., Hsu, C. L., \& Kuo, N. T. (2010). The effect of service convenience on postpurchasing behaviours. Industrial Management \& Data Systems. 110(9), 1420-1443.

Chen, C. F., \& Chen, F. S. (2010). Experience quality, perceived value, satisfaction and behavioral intentions for heritage tourists. Tourism Management, 31(1), 29-35.

Choi, C., Greenwell, T. C., \& Lee, K. (2018). Effects of service quality, perceived value, and consumer satisfaction on behavioral intentions in virtual golf. Journal of Physical Education and Sport, 18(3), 14591468 .

Dauda, S. Y., \& Lee, J. (2016). Quality of service and customer satisfaction: A conjoint analysis for the Nigerian bank customers. International Journal of Bank Marketing. 34(6), 841-867.

Eggert, A., \& Ulaga, W. (2002). Customer perceived value: A substitute for satisfaction in business markets?. Journal of Business \& Industrial Marketing. 17(2/3), 107-118.

Elmayar, A. (2011) Assessing the perceived service quality levels in the libyan private and public banking sectors: A customer perspective. Doctoral Thesis, Northumbria University.

Fornell, C., \& Larcker, D. F. (1981). Evaluating structural equation models with unobservable variables and measurement error. Journal of Marketing Research, 18(1), 39-50.

García-Fernández, J., Gálvez-Ruíz, P., Fernández-Gavira, J., Vélez-Colón, L., Pitts, B., \& Bernal-García, A. (2018). The effects of service convenience and perceived quality on perceived value, satisfaction and loyalty in low-cost fitness centers. Sport Management Review, 21(3), 250-262.

George, A., \& Kumar, G. G. (2014). Impact of service quality dimensions in internet banking on customer satisfaction. Decision, 41(1), 73-85.

Hair, J., Hult, G. T. M., Ringle, C. \& Sarstedt, M. (2014). A primer on partial least squares structural equation modeling (PLS-SEM). CA: Thousands Oaks, Sage.

Han, H., \& Ryu, K. (2012). Key factors driving customers' word-of-mouth intentions in full-service restaurants: The moderating role of switching costs. Cornell Hospitality Quarterly, 53(2), 96-109. 
Han, H., Al-Ansi, A., Olya, H. G., \& Kim, W. (2019). Exploring halal-friendly destination attributes in South Korea: Perceptions and behaviors of Muslim travelers toward a non-Muslim destination. Tourism Management, 71, 151-164.

Hayes A. F. (2013). Introduction to mediation, moderation, and conditional process analysis: A regressionbased approach. New York: Guilford Press

Hellier, P. K., Geursen, G. M., Carr, R. A., \& Rickard, J. A. (2003). Customer repurchase intention. European Journal of Marketing. 37(11/12), 1762-1800.

Hussain, R., Al Nasser, A., \& Hussain, Y. K. (2015). Service quality and customer satisfaction of a UAE-based airline: An empirical investigation. Journal of Air Transport Management, 42(1), 167-175.

Islam, T., Rahman, S., \& Nahar, N. (2015). Factors affecting customer satisfaction in 3G service. American Scientific Research Journal for Engineering, Technology, and Sciences (ASRJETS), 14(3), 202-217.

Ismail, A., Abdullah, M. M. B., \& Francis, S. K. (2009). Exploring the relationships among service quality features, perceived value and customer satisfaction. Journal of Industrial Engineering and Management (JIEM), 2(1), 230-250.

İstanbul Valiliği (2020). http://www.istanbul.gov.tr/Files/ebulten/201710/icerik\%C3\%BCniversite.html, Erişim tarihi 22.112020

Jeaheng, Y., Al-Ansi, A., \& Han, H. (2020). Impacts of Halal-friendly services, facilities, and food and Beverages on Muslim travelers' perceptions of service quality attributes, perceived price, satisfaction, trust, and loyalty. Journal of Hospitality Marketing \& Management, 7(29),1-25.

Jhandir, S. U. (2012). Customer satisfaction, perceived service quality and mediating role of perceived value. International journal of Marketing Studies, 4(1), 68-76.

Konuk, F. A. (2019). The influence of perceived food quality, price fairness, perceived value and satisfaction on customers' revisit and word-of-mouth intentions towards organic food restaurants. Journal of Retailing and Consumer Services, 50, 103-110.

Lai, F., Griffin, M., \& Babin, B. J. (2009). How quality, value, image, and satisfaction create loyalty at a Chinese telecom. Journal of Business Research, 62(10), 980-986.

Lee, D. H. \& Cheng, (2015), Examining the relationships between corporate performance of convention and exhibition centers, service quality, and customer satisfaction, International Journal of Tourism and Hospitality Research, 29(1), 61-74. 
Lee, D. H. (2019). The impact of exhibition service quality on general attendees' satisfaction through distinct mediating roles of perceived value. Asia Pacific Journal of Marketing and Logistics, 32(3), 793-816.

Lewin, K. (1938), The Conceptual Representation and Measurement of Psychological Forces, Duke University Press, Durham, NC.

Lim, D. H., \& Morris, M. L. (2006). Influence of trainee characteristics, instructional satisfaction, and organizational climate on perceived learning and training transfer. Human Resource Development Quarterly, 17(1), 85-115.

lmayar, A. (2011) Assessing the perceived service quality levels in the libyan private and public banking sectors: A customer perspective. Doctoral thesis, Northumbria University.

Mason, M. C., \& Paggiaro, A. (2012). Investigating the role of festivalscape in culinary tourism: The case of food and wine events. Tourism Management, 33(6), 1329-1336.

Mbango, P., \& Toerien, D. F. (2019). The role of perceived value in promoting customer satisfaction: Antecedents and consequences. Cogent Social Sciences, 5(1), 1-16.

Momotaz, S. N. (2019). Effects of service quality and perceived value on customer satisfaction to mobile internet service: Evidence from Bangladesh. International Review of Business Research Papers, 15(1), 60-68.

Nunnally, J. C. \& Bernstein, I. H. (1994). The theory of measurement error. In: Psychometric theory. (3rd Ed.). New York: McGraw-Hill, 1994:209- 47, 3, 209-247.

Oriade, A. D. (2013). An empirical investigation of the relationship between perceived quality, value, satisfaction and behavioural intentions among visitors to UK attractions (Doctoral dissertation, University of Salford).

Özbek, V. (2016). Algılanan risk ve algılanan değer arasındaki İlişkide algılanan hizmet kalitesinin düzenleyici etkisi. International Review of Economics and Management, 4(3), 62-83.

Parasuraman, A., Zeithaml, V. A., \& Berry, L. L. (1988). SERVQUAL: A multiple-item scale for measuring consumer perceptions of service quality. Journal of Retailing, 64(1), 12-40

Raza, M. A., Siddiquei, A. N., Awan, H. M., \& Bukhari, K. (2012). Relationship between service quality, perceived value, satisfaction and revisit intention in hotel industry. Interdisciplinary Journal of Contemporary Research in Business, 4(8), 788-805.

Samudro, A., Sumarwan, U., Simanjuntak, M., \& Yusuf, E. (2020). Assessing the effects of perceived quality and perceived value on customer satisfaction. Management Science Letters, 10(5), 1077-1084. 
Slack, N., Singh, G., \& Sharma, S. (2020). Impact of perceived value on the satisfaction of supermarket customers: developing country perspective. International Journal of Retail \& Distribution Management, 48(11), 1235-1254.

Spathis, C., Petridou, E., \& Glaveli, N. (2004). Managing service quality in banks: customers' gender effects. Managing Service Quality: An International Journal, 14(1), 90-102.

Sürücü, L., \& Maslakçı, A. (2020). Validity and reliability in quantitative research. Business $\mathcal{E}$ Management Studies: An International Journal, 8(3), 2694-2726.

Sürücü, L., Yeşilada, F., \& Maslakcı, A. (2020). Purchasing Intention: A Research on Mobile Phone Usage by Young Adults. The Journal of Asian Finance, Economics and Business (JAFEB), 7(8), 353-360.

Tabachnick, B. G., Fidell, L. S., \& Ullman, J. B. (2007). Using multivariate statistics (Vol. 5, pp. 481-498). Boston, MA: Pearson.

Turel, O., \& Serenko, A. (2006). Satisfaction with mobile services in Canada: An empirical investigation. Telecommunications Policy, 30(5-6), 314-331.

Uddin, M. B., \& Akhter, B. (2012). Customer satisfaction in mobile phone services in Bangladesh: A survey research. Management $\mathcal{E}$ Marketing Journal, 10(1), 20-36.

Wang, Y., Lo, H. P., \& Hui, Y. V. (2003). The antecedents of service quality and product quality and their influences on bank reputation: evidence from the banking industry in China. Managing Service Quality: An International Journal, 13(1), 72-83.

Wu, C. H. J., \& Liang, R. D. (2009). Effect of experiential value on customer satisfaction with service encounters in luxury-hotel restaurants. International Journal of Hospitality Management, 28(4), 586-593.

Žabkar, V., Brenčič, M. M., \& Dmitrović, T. (2010). Modelling perceived quality, visitor satisfaction and behavioural intentions at the destination level. Tourism Management, 31(4), 537-546.

Zeithaml, V. A. (1988). Consumer perceptions of price, quality, and value: a means-end model and synthesis of evidence. Journal of Marketing, 52(1), 2-22. 